\title{
Improved blastocyst development of single cow OPU-derived presumptive zygotes by group culture with agarose-embedded helper embryos
}

\author{
Gautam Kumar Deb ${ }^{1 \dagger}$, Jong In Jin ${ }^{1 \dagger}$, Tae Hyun Kwon ${ }^{1}$, Byung Hyun Choi ${ }^{1}$, Jae II Bang ${ }^{1}$, Shukla Rani Dey ${ }^{1}$,
} In Rae Cho ${ }^{2}$ and II Keun Kong ${ }^{1,3^{*}}$

\begin{abstract}
Background: The in vitro culture of presumed zygotes derived from single cow ovum pick-up (OPU) is important for the production of quality blastocysts maintaining pedigree. The aim of the present study was to evaluate the agar chip-embedded helper embryo coculture system for single cow OPU-derived zygotes by assessing embryo quality.

Methods: Cumulus oocyte complexes (COCs) were collected from Hanwoo cows with high genetic merit twice a week using the ultra-sound guided OPU technique and from slaughterhouse ovaries. The Hanwoo cow COCs and slaughterhouse ovaries were matured in vitro, fertilized in vitro with thawed Hanwoo sperm and cultured for $24 \mathrm{~h}$. The presumed zygotes were subsequently placed in three different culture systems: (1) control OPU (controlOPU) with single cow OPU-derived presumed zygotes (2 8); (2) agar chip-embedded slaughterhouse helper embryo coculture (agarOPU) with ten presumed zygotes including all presumed zygotes from a cow (2 8) and the rest from agar chip-embedded slaughterhouse presumed zygotes (8 2); and (3) slaughterhouse in vitro embryo production (sIVP) with ten slaughterhouse ovary-derived presumed zygotes, each in $50 \mu \mathrm{L}$ droplets. Day 8 blastocysts were assayed for apoptosis and gene expression using real time PCR.
\end{abstract}

Results: The coculture system promoted higher blastocyst development in OPU zygotes compared to control OPU zygotes cultured alone (35.2 vs. 13.9\%; P < 0.01). Genes predicted to be involved in implantation failure and/or embryo resorption were down-regulated $(P<0.05)$ in control OPU zygotes $(C D 9$, 0.4-fold; $A K R A B 1,0.3$-fold) and in cocultured zygotes (CD9, 0.3-fold; AKRAB1, 0.3-fold) compared to sIVP blastocysts (1.0-fold). Moreover, genes involved in implantation and/or normal calf delivery were up-regulated $(P<0.05$ to $P<0.01)$ in control OPU zygotes (PGSH2, 5.0-fold; TXN, 4.3-fold; PLAU, 1.7-fold) and cocultured zygotes (PGSH2, 14.5-fold; TXN, 3.2-fold; PLAU, 6.8-fold) compared to sIVP (1.0-fold) blastocysts. However, the expression of PLAC8, TGF- $\beta 1$, ODC1, ATP5A1 and CASP3 did not differ between the three culture groups.

Conclusions: Results show that the agar chip-embedded helper embryo coculture system enhances developmental competence and embryo quality in cultures of limited numbers of high pedigree single cow OPU presumed zygotes.

\footnotetext{
* Correspondence: ikong@gnu.kr

† Contributed equally

${ }^{1}$ Division of Applied Life Science (BK21 program), Graduate School of

Gyeongsang National University, Jinju 660-701, Republic of Korea

Full list of author information is available at the end of the article
} 


\section{Background}

Ultrasound-guided transvaginal ovum pick-up (OPU) in combination with conventional in vitro fertilization (IVF) has enabled the production of large numbers of embryos from high genetic merit donors of different ages and physiological conditions [1-3]. Therefore, the OPU technique combined with IVF has the potential to improve genetic progress through the maternal lineage [4]. The efficiency of OPU-based in vitro embryo production (IVP) ranges between $11 \%$ in untreated cows to $30 \%$ in hormone-treated cows $[2,5-8]$. The number of COCs collected from a single cow during an OPU session varies from $<3$ in non-stimulated cows [5] to $>9$ in hormone-stimulated cows [8]. Approximately $50 \%$ of all OPU-derived COCs are of poor quality $[5,8]$. A culture system promoting consistent high blastocyst development and maintaining pedigree would be crucial to cattle breeding programs.

A minimal number of presumed bovine zygotes must be cultured within a droplet in order to maximize embryo developmental competence and quality by maintaining appropriate autocrine and paracrine signaling $[9,10]$. In a recent study, Senatore et al. [11] showed that agar-embedded helper embryos can improve the developmental competence of OPU oocytes. This novel finding suggested that agar-embedded slaughterhouse ovary-derived presumed zygotes may be cultured with small numbers of single cow OPU presumed zygotes to improve OPU embryo development and quality. However, the quality of the embryos derived by this technique remains to be evaluated. Culture conditions can modulate the expression of genes that affect embryo quality [12-17]. The quality of pre-attached blastocysts is usually predicted from the total number of blastomeres, the proportion of inner cell mass and the percentage of apoptotic blastomeres [18]. However, these criteria do not always ensure high calf output after embryo transfer. Improvements in quantitative real time PCR enabled the identification of several molecular markers of pre-implantation embryo quality, including genes involved in metabolic activity, stress response and reprogramming [19]. The expression pattern of thioredoxin $(T X N)$, placenta-specific 8 (PLAC8), prostaglandin $\mathrm{G} / \mathrm{H}$ synthase-2 (PGSH2), urokinase-type plasminogen activators $(P L A U)$, ornithine decarboxylase $(O D C 1)$, the alpha subunit of ATP synthase isoform 5 A1 (ATP5A1), aldoketo reductase family 1 member $\mathrm{B} 1$ (AKR1B1) and CD9 $(C D 9)$ in bovine blastocysts reliably predicts quality in terms of implantation, early embryo loss/resorption and normal calf delivery [20]. Transforming growth factor beta $1(T G F-\beta 1)$ was identified at the fetal-maternal interface and plays crucial roles during the post-transfer development of embryos [21].
The aim of the present study was to determine whether agar chip-embedded slaughterhouse-derived helper embryos may enhance the developmental competence and quality of single cow OPU-derived presumed zygotes in coculture.

\section{Methods \\ Reagents}

Unless otherwise indicated, all chemicals and media were purchased from Sigma Chemical Co. (St. Louis, MO, USA).

\section{Experimental design}

Three different culture systems were tested to evaluate embryo development in OPU and slaughterhouse presumed zygotes including: (1) "control OPU (controlOPU)" with single cow OPU derived presumed zygotes (2 8 depending on availability), (2) "agar chip embedded slaughterhouse helper embryo coculture (agarOPU)" with a threshold of total ten presumed zygotes including all presumed zygotes from a donor cow (2 8 depending on availability) and the rest from agar chip embedded slaughterhouse presumed zygotes ( $8 \sim 2$ depending on OPU presumed zygotes) and (3) "slaughterhouse IVP control (sIVP)" with ten presumed slaughterhouse derived zygotes each in $50 \mu \mathrm{L}$ droplets of IVC medium. In vitro maturation, IVF and IVC (up to $24 \mathrm{~h}$ ) were performed with single cow OPU COCs, each in $50 \mu \mathrm{L}$ droplets. A detailed experimental design is presented in Figure 1. The COCs of alternative OPU sessions were used either in control OPU cultures (controlOPU) or in cocultures (agarOPU). The slaughterhouse COCs were pre-treated with $2 \mathrm{mM}$ 6-dimethylaminopurine (DMAP) for $6 \sim 7 \mathrm{~h}$ to generate agar chip-embedded helper embryos or used for continued in vitro culture (dmapIVP) to evaluate developmental rates and embryo quality in response to DMAP.

\section{Oocyte donors}

Two sets of four- to six-year-old Hanwoo cows (three cows per set) of high pedigree were used as oocyte donors. The cows were housed in a barn and fed commercially available concentrate pellets and straw, with fresh water provided ad libitum. Experimental cows were housed together in an open stall, in the same environmental conditions. The experimental cows had functional ovaries during the experimental period, as confirmed by transrectal palpation. The experimental procedures were approved by the Gyeongsang National University Association for the Accreditation of Laboratory Animal Care. The first set of donor cows was used for 22 OPU sessions and the second set for eight sessions. 


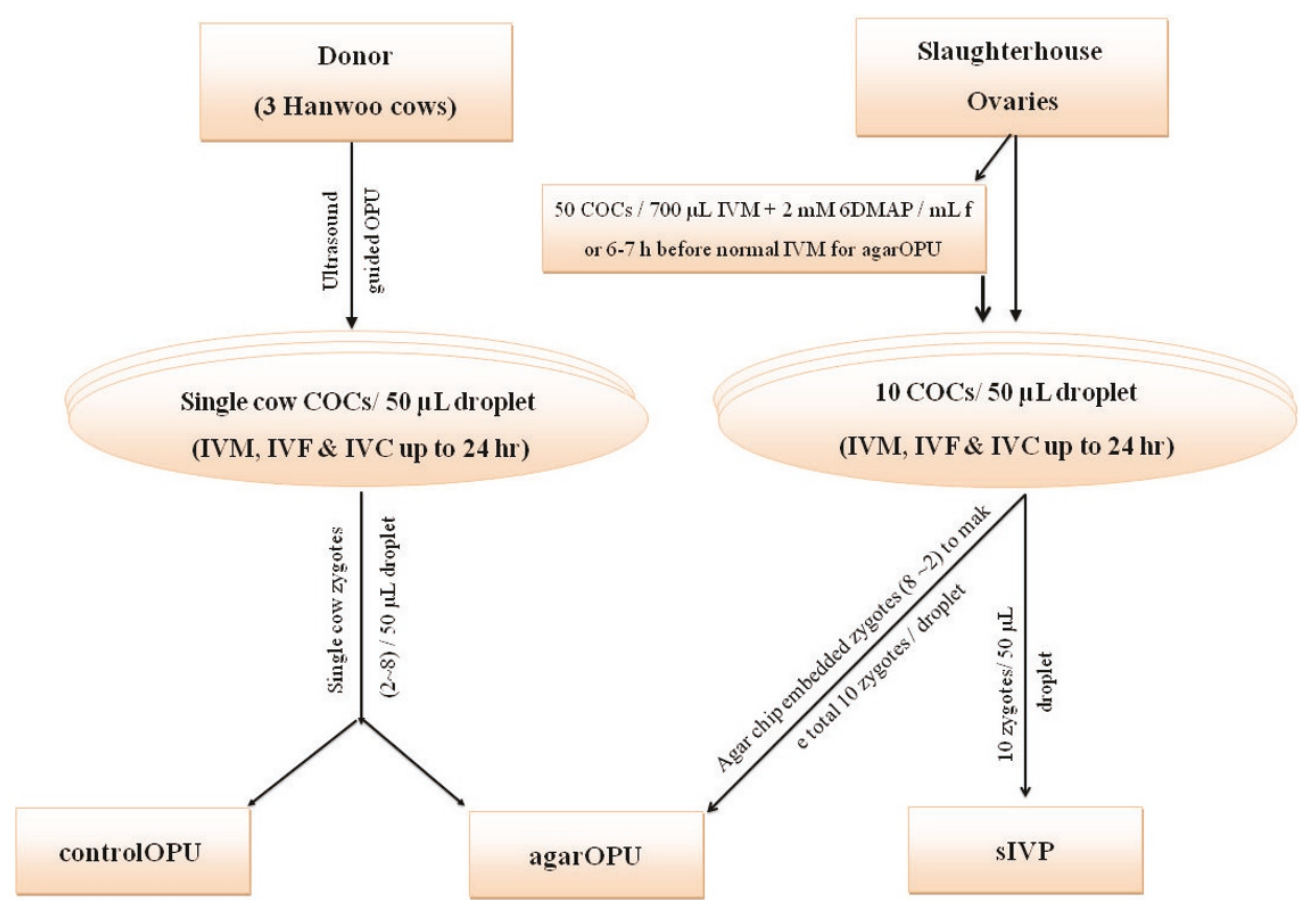

Figure 1 Schematic representation of experimental design. During an OPU session, all COCs retrieved from a single cow were subjected to in vitro maturation (IVM), in vitro fertilization (IVF) and in vitro culture (IVC-I) for up to $24 \mathrm{~h}$. After $24 \mathrm{~h}$ of IVC, the presumed OPU zygotes were cultured either (1) alone (2 8) or (2) cocultured (2 8) with agar chip-embedded slaughterhouse presumed zygotes (8 2). Moreover, a group of ten slaughterhouse-derived presumed zygotes were cultured (sIVP) to supply presumed zygotes for coculturing with OPU presumed zygotes or for the evaluation of embryonic development.

\section{Ovum pick-up}

A twice/week OPU schedule was followed throughout the experimental period, without subjecting the cows to hormonal stimulation. Follicles were visualized using an ultrasound scanner equipped with a $6.5 \mathrm{Mhz}$ sectorial probe (Madison, WI, USA) fitted in a custom made intra-vaginal OPU probe-holder. An 18 gauge disposable hypodermic needle (Cook Veterinary Products, Queensland, Australia) connected to a $50 \mathrm{~mL}$ conical tube (BD Falcon, NJ, USA) by Teflon tubing (Cook Veterinary Products) was used for follicular puncture. Negative pressure was applied using a vacuum aspiration pump (GAST, MI, USA) and the aspiration vacuum was adjusted to a flow rate of $15 \mathrm{~mL}$ of water per minute. The COC collection tube and aspiration medium were kept at $38^{\circ} \mathrm{C}$ in a water bath. Oocytes were collected in Tyrodes lactate (TL)-Hepes medium enriched with $2 \%$ (v/v) fetal calf serum, $100 \mathrm{iu} / \mathrm{mL}$ penicillin, $0.1 \mathrm{mg} / \mathrm{mL}$ streptomycin and $5 \mathrm{iu} / \mathrm{mL}$ heparin. To minimize abdominal straining during OPU, epidural anesthesia was performed with $5 \mathrm{~mL}$ of lidocaine (Je-Il Pharmaceutical, Daegu, Republic of Korea). Follicles $\geq 3 \mathrm{~mm}$ in diameter were punctured during each OPU session.

\section{In vitro maturation (IVM)}

The follicular fluid collected in TL-Hepes in $50 \mathrm{~mL}$ conical tubes was decanted into an EM-CON embryo filter (Agtech Inc., Spring Valley, WI, USA) and the oocytes were isolated under a stereomicroscope. The oocyte recovery rate was calculated as the number of oocytes recovered and expressed as the percentage of the total follicles aspirated for each cow. The oocytes were divided into four groups according to the presence or absence of cumulus cells surrounding the oocytes and their cytoplasmic configuration [22]. All COCs from a single cow were washed in TL-Hepes before a final wash in maturation medium and transferred into $50 \mu \mathrm{L}$ droplets of IVM medium (TCM199 supplemented with $10 \%(\mathrm{v} / \mathrm{v})$ fetal bovine serum (FBS), $1 \mu \mathrm{g} / \mathrm{mL} \beta$-estradiol, $10 \mu \mathrm{g} / \mathrm{mL}$ FSH, $0.6 \mathrm{mM}$ cystein and $0.2 \mathrm{mM} \mathrm{Na-pyru-}$ vate) for $22 \sim 24 \mathrm{~h}$ under mineral oil.

\section{In vitro fertilization (IVF)}

Frozen-thawed Hanwoo spermatozoa from a single batch of semen were used throughout the study. Sperm preparation procedures were described previously [23]. Briefly, thawed sperm was washed with Dulbecco's PBS 
and incubated with $20 \mu \mathrm{g} / \mathrm{mL}$ heparin sodium salt in IVF medium (Tyrode's lactate solution supplemented with $6 \mathrm{mg} / \mathrm{mL}$ fatty acid-free bovine serum albumin (BSA), $22 \mu \mathrm{g} / \mathrm{mL}$ sodium pyruvate, $100 \mathrm{iu} / \mathrm{mL}$ penicillin and $0.1 \mathrm{mg} / \mathrm{mL}$ streptomycin) for $15 \mathrm{~min}$. The presumptive capacitated spermatozoa were finally diluted to $1 \times$ $10^{6}$ spermatozoa $/ \mathrm{mL}$ of IVF medium. The matured COCs were cocultured with the presumptive capacitated sperm in a $50 \mu \mathrm{L}$ droplet of IVF medium for $18 \sim 20 \mathrm{~h}$.

\section{In vitro culture (IVC)}

Eighteen to twenty hours after fertilization the cumulus cells surrounding the zygotes were denuded by pipetting in TL-Hepes medium in a $35 \mathrm{~mm}$ culture dish (SPL Life Sciences, Gyeonggi-do, Republic of Korea) with finely stretched pasteur pipettes. Presumed zygotes from individual cows (minimum two per cow during an OPU session) were then transferred into $50 \mu \mathrm{L}$ droplets of modified CR1-aa [24] supplemented with $44 \mu \mathrm{g} / \mathrm{mL} \mathrm{Na-}$ pyruvate, $14.6 \mu \mathrm{g} / \mathrm{mL}$ glutamine, $100 \mathrm{iu} / \mathrm{mL}$ penicillin, $0.1 \mathrm{mg} / \mathrm{mL}$ streptomycin, $3 \mathrm{mg} / \mathrm{mL}$ BSA and $310 \mu \mathrm{g} / \mathrm{mL}$ glutathione (IVC-I medium) for $24 \mathrm{~h}$, and then cultured in medium in which the BSA had been replaced with $10 \%(\mathrm{v} / \mathrm{v})$ FBS (IVC-II medium) until day 8 (day 0: day of IVF). BSA was replaced with FBS earlier than in a conventional CR1aa-based IVC system because it was difficult to handle agar-embedded embryos once they had been transferred to the IVC medium. Fifty percent of the medium was changed with fresh IVC-II medium at day 6.

Droplets of medium covered with mineral oil (M8410 ) were pre-incubated for at least $2 \mathrm{~h}$ at $38.5^{\circ} \mathrm{C}$ in an atmosphere of $5 \% \mathrm{CO}_{2}$ in humidified air. Cleavages and blastocyst development rates were evaluated as the proportion of OPU-derived presumed zygotes at day 3 and day 7 post-insemination, respectively. Day 8 blastocysts from the three donor cows were pooled and washed three times in PBS before being snap frozen in liquid nitrogen and stored at $-80^{\circ} \mathrm{C}$ until RNA extraction or fixed in $4 \%(\mathrm{v} / \mathrm{v})$ paraformaldehyde in PBS and kept at $4^{\circ} \mathrm{C}$ until the detection of blastomeres.

\section{Synchronization of slaughterhouse oocytes}

The slaughterhouse COCs were aspirated as described previously [23]. Only grade 1 and 2 oocytes were used for subsequent IVM/IVF/IVC. To coordinate the culture schedule of OPU-derived COCs, the maturation of slaughterhouse COCs was suppressed by incubation with 2 mM DMAP in IVM medium for $6 \sim 7 \mathrm{~h}$ (50 COCs $/ 700 \mu \mathrm{L}$ ) before the COCs were washed in IVM medium and then transferred into the final IVM droplets (10 COCs $/ 50 \mu \mathrm{L}$ droplet). The IVF and IVC procedures were the same as those described above for OPU oocytes.

\section{Preparation of agar-embedded helper embryos}

Agar-embedded helper embryos were prepared according to Senatore et al. [11] with modification. Briefly, one gram of agarose (Type VII A9045) was added to $100 \mathrm{~mL}$ D-PBS and melted on a portable lab stove. Once melted, the agarose solution was aliquoted into ten $10-\mathrm{mL}$ conical tubes (BD Falcon) and stored at $4^{\circ} \mathrm{C}$ until use. Before use, the agarose was again melted by heating at $60^{\circ} \mathrm{C}$ and was placed in an incubator set at $36 \sim 38{ }^{\circ} \mathrm{C}$. The solution was poured into the wells of a 4-well dish (SPL Life Sciences) and the slaughterhouse zygotes were washed four to five times in the agar solution using a pasteur pipette with an opening a little larger than the diameter of an embryo. Once the agarose surrounding the zygotes solidified, the agar-embedded zygotes were transferred into wells already containing the OPU zygotes in culture medium (Figure 2).

To avoid possible disease transmission to OPU blastocysts from slaughterhouse embryos, ovaries were collected from physically healthy cows and transferred to the lab in separate flasks from those commonly used for IVP. Ovaries bearing blood-filled follicles were not used for $\mathrm{COC}$ aspiration. Before aspiration, the ovaries were washed several times in physiological saline. The aspirated COCs were washed two to three times in TLHepes containing antibiotic $(100 \mathrm{iu} / \mathrm{mL}$ penicillin and $0.1 \mathrm{mg} / \mathrm{mL}$ streptomycin) and underwent a final wash in maturation medium. Moreover, slaughterhouse presumed zygotes were washed in IVC-I medium four to five times before being embedded in agar chips.

\section{Terminal deoxynucleotidyl transferase dUTP nick end labeling (TUNEL) staining}

The number of blastomeres and the percentage of apoptotic blastomeres in day 8 blastocysts were detected by TUNEL staining using the In Situ Cell Death Detection Kit (Fluorescein; Roche Diagnostics Corp.; Indianapolis, IN, USA) as described previously [25]. Briefly, fixed embryos were washed twice with $0.3 \%(\mathrm{w} / \mathrm{v})$ polyvinylpyrrolidone (PVP) in $1 \mathrm{M}$ PBS (PVP-PBS) before being incubated in $0.5 \%(\mathrm{v} / \mathrm{v})$ Triton X-100 in $0.1 \%(\mathrm{w} / \mathrm{v})$ sodium citrate for $30 \mathrm{~min}$ at room temperature. After permeabilization, the embryos were washed twice in PVP-PBS and incubated in the dark in fluorescence-conjugated dUTP and terminal deoxynucleotide transferase for $1 \mathrm{~h}$ at room temperature. These TUNEL-stained embryos were then washed in PVP-PBS and incubated in PVP-PBS containing $10 \mu \mathrm{g} / \mathrm{mL}$ Hoechst 33342 for 10 min. Washing was then performed twice in PVP-PBS to remove excess Hoechst 33342 and the blastocysts were mounted on glass slides under cover slips to evaluate their nuclear configuration. The number of blastomeres in each blastocyst was counted under an epifluorescence microscope equipped with a mercury lamp. TUNEL- 


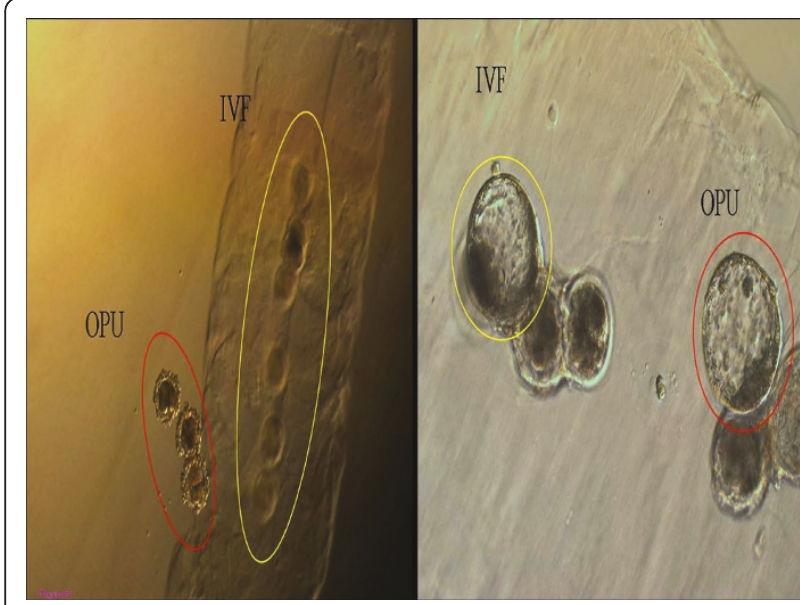

Figure 2 Agar chip-embedded slaughterhouse helper embryo coculture for ovum pick-up (OPU) presumed zygotes. IVF: slaughterhouse in vitro embryo production system. Ovals show OPU (red) and agar chip-embedded IVF (yellow) zygotes in a $50 \mu \mathrm{L}$ droplet. Circles represent blastocysts developed from OPU (red) or IVF (yellow) zygotes.

positive cells displayed bright red fluorescence. The total number of blastomeres was determined by the extent of green/blue fluorescence. The number of blastocysts subjected to TUNEL staining was seven for the controlOPU group, ten for the agarOPU group, 11 for the sIVP group and 20 for the dmapIVP group. Blastocysts of controlOPU (7), agarOPU (10) and sIVP (10) stained with $10 \mu \mathrm{g} / \mathrm{mL}$ Hoechst 33342 for 10 min during preliminary experiments were also included in the calculation of total blastomere numbers.

\section{Gene expression analysis}

Messenger RNA (mRNA) was extracted from three sets (two to three day- 8 blastocysts per set) of blastocyst samples for each group (controlOPU, agarOPU and sIVP) using Dynabeads mRNA Direct Kit (Dynal AS, Oslo, Norway) according to Deb et al. [25]. The mRNA samples were reverse transcribed in a final volume of 20 $\mu \mathrm{L}$ using iScript cDNA Synthesis Kit (Bio-Rad Laboratories, Hercules, CA, USA) according to the manufacturers' instructions. The cDNA was diluted by adding $30 \mu \mathrm{L}$ RNase-free water per embryo equivalent. The limited yields of mRNA prevented any assessment of RNA integrity.

The primers were designed and tested for specificity using the Primer Designing Tool [26] and are shown in Table 1. qPCR was performed in duplicate in a CFX98 instrument (Bio-Rad Laboratories) using a $10 \mu \mathrm{L}$ reaction mixture containing $0.2 \mathrm{mM}$ of each bovine-specific primer, $1 \times$ iQ SYBR Green Supermix (iQ SYBR Green Supermix kit, Bio-Rad Laboratories) and $1.0 \mu \mathrm{L}$ of diluted cDNA. The cycling conditions were as follows: $95^{\circ} \mathrm{C}$ for 3 min followed by 44 cycles of $15 \mathrm{~s}$ at $95^{\circ} \mathrm{C}, 20$ $\mathrm{s}$ at $57^{\circ} \mathrm{C}$ and $30 \mathrm{~s}$ at $72^{\circ} \mathrm{C}$, and a final extension of 5 min at $72^{\circ} \mathrm{C}$. Amplification was followed by a melting curve analysis using progressive denaturation during which the temperature was raised from 65 to $95^{\circ} \mathrm{C}$ at a transition rate of $0.5^{\circ} \mathrm{C}$ per second. A negative control (NTC) was performed for each gene. The target genes were quantified by the $\Delta \Delta \mathrm{c}(\mathrm{t})$ method using CFX manager V1.1 software (Bio-Rad Laboratories). Normalization was performed against two reference genes selected among four (ACTB, 18s rRNA, GAPDH and YWHAZ) that were tested with the target genes (CD9, AKR1B1, PGSH2, TXN, PLAU, PLAC8, ODC1, TGF-B1, ATP5A1, and $C A S P 3)$. The average $\mathrm{CV}$ for the reference genes was 0.2286 . The average $M$-value was 0.0816 for the blastocyst samples. The low M-value indicates the stability of the reference genes. PCR efficiency was calculated for each gene using relative calibration curves prepared from bovine uterine cDNA using a 10-fold dilution series in five points. The standard curves yielded correlation coefficients greater than 0.98 and reaction efficiencies between 90 and $110 \%$. The qPCR was performed once with each three biological samples and at least one time with pooled cDNA from the three biological samples. The mean of four replicates was used for statistical analysis.

\section{Statistical analysis}

Data were analyzed using one way analysis of variance (ANOVA) and Duncan's Multiple Comparison Test using the SPSS program (Version 11.5; SPSS Inc., Chicago, IL, USA). However, the chi-square test was used to analyze oocyte recovery rate, percent of high quality oocytes (grade $1+2$ ), cleavage and blastocyst development rate. Differences were considered significant at the $5 \%$ level unless otherwise indicated. Data were expressed as mean \pm standard deviation.

\section{Results}

\section{Follicle and oocyte dynamics}

A total of 578 follicles were punctured during 30 OPU sessions from two sets of three cows (22 sessions for the first set and eight sessions for the second set), yielding 400 oocytes. The number of follicles punctured and of oocytes recovered per Hanwoo cow during an OPU session was $6.4 \pm 2.1$ (with a range of 2 to 10 ) and $4.4 \pm$ 1.8 (with a range of 2 to 8 ), respectively. The oocyte recovery rate was $69.3 \%$, of which $49.2 \%$ was of high quality (grade 1 and 2).

\section{In vitro embryo development efficiency}

Development rates up to the cleavage stage did not differ between the controlOPU group and the agarOPU group; however, blastocyst development rates were 
Table 1 Primers used for quantitative real-time PCR analysis

\begin{tabular}{|c|c|c|c|c|}
\hline Gene name & GeneBank accession number & Forward primer $\left(5^{\prime}-3^{\prime}\right)$ & Reverse primer $\left(5^{\prime}-3^{\prime}\right)$ & Product length (base pairs) \\
\hline$A K R 1 B 1$ & BT021058 & TGCAACCCAAATACTCTITT & AAAAGCCTAGCTGAAAGGAT & 106 \\
\hline ATP5A1 & M_174684.2N & GACCGATGGAAAGATCTCAG & AACCACCAAGCAACATGG & 212 \\
\hline CD9 & NM_173900 & AGATCTTCCGAAGCAAATTC & CAAAGTTAGTGGCAAAGGAA & 238 \\
\hline ODC1 & NM_174130.2 & CTATGTGATGTCAGGGCCAA & CACGTTAATACGCGTGGAAG & 166 \\
\hline PGSH2 & NM_174445 & ATCCTCCCACAGTCAAAGAT & GCACATCACACACTCTGTTG & 162 \\
\hline PLAC8 & NM_001025325 & TCTGACATTITTACCGCTCT & ATTTCATTGCAGCATTTTCT & 131 \\
\hline PLAU & NM_174147.2 & ATCCCTCTGACTATCGCTAC & CAGGAATCTGTITCCCACTG & 151 \\
\hline$T G F \beta 1$ & NM_001166068.1 & TGGAGCTGTACCAGAAATATAGCAA & GCCACTGCCGCACAACTC & 120 \\
\hline TXN & AF104105 & TGATCAAGCCTITCTITCAT & TAATGGTGGCTTCAAGTTTT & 195 \\
\hline
\end{tabular}

AKR1B1: aldo-keto reductase family 1, member B1; ATP5A1: alpha subunit ATP synthase isoform 5 A1; CD9: CD9 molecule; ODC1: ornithine decarboxylase; PLAU: urokinase-type plasminogen activators; PGSH2: prostaglandin G/H synthase-2; PLAC8: placenta-specific 8; TGF $\beta 1$ : transforming growth factor beta 1; TXN: thioredoxin.

Primer sequences for 18s ribosomal RNA (18srRNA), beta actin (ACTB), caspase3 (CASP3), glyceraldehyde-3-phosphate dehydrogenase (GAPDH) and tyrosine 3monooxygenase/tryptophan 5-monooxygenase activation protein, zeta polypeptide (YWHAZ) were published previously [25].

higher in the agarOPU group than in the controlOPU group $(\mathrm{P}<0.01)$. The cleavage and blastocyst development efficiency of the agarOPU group was similar to that of the sIVP culture system (Table 2). Moreover, the exposure of immature slaughterhouse COCs to DMAP for $6 \sim 7 \mathrm{~h}$ before IVM did not affect the cleavage and blastocyst development rates (Table 2).

\section{Blastomere numbers}

The total number of blastomeres and the percentage of apoptotic blastomeres in the blastocysts did not differ ( $P$ $>0.05$ ) between the controlOPU, agarOPU and sIVP groups (Table 2). Moreover, inhibition of maturation by DMAP did not affect the total number of blastomeres or the percentage of apoptotic blastomeres in the blastocysts (Table 2).

\section{Gene expression}

The differential expression of selected genes was investigated by quantitative real time PCR. Expression was normalized to at least two reference genes. The expression of CD9, AKR1B1, PGSH2, TXN and PLAU in blastocysts derived from the controlOPU, agarOPU and sIVP culture systems is presented in Figure 3 . The expression of CD9 and $A K R 1 B 1$ was higher in sIVP blastocysts than in controlOPU and agarOPU blastocysts (Figure 3). By contrast, the expression of PGSH2, ATP5A1 and PLAU was higher in agarOPU blastocysts than in controlOPU and sIVP blastocysts (Figure 3 ). The expression of TXN was higher in OPU-derived blastocysts (controlOPU and agarOPU) than in sIVP blastocysts. However, the expression of PLAC8 (2.1- vs. 3.8vs. 1.0-fold), TGF $\beta 1$ (0.8- vs. 0.7 - vs. 1.0-fold), $O D C 1$ (1.1- vs. 1.2 - vs. 1.0 -fold), ATP5A1 (0.8- vs. 1.1 - vs. 1.0 fold) and CASP3 (0.8- vs. 0.8- vs. 1.0-fold) did not differ $(\mathrm{P}>0.05)$ between the controlOPU, agarOPU and sIVP groups, respectively.

\section{Discussion}

One of the challenges of the OPU-IVF technique is the scare of the COCs per culture droplet, particularly when small numbers of single cow COCs are used for in vitro embryo production. Recently Senatore et al. [11] developed the agar chip-embedded helper embryo coculture system for small numbers of OPU-derived presumed zygotes. The present study confirms that agar chipembedded helper embryo coculture not only improves the blastocyst development rates of single cow OPU presumed zygotes but also maintains blastocyst quality as defined by blastomere numbers, the percentage of apoptotic blastomeres and blastocyst gene expression.

In the present study, 2 8 OPU-derived COCs were available for IVP per OPU session. Considering the limited number of COCs retrieved per cow, all of the presumed zygotes of a cow (2 8 per session) were used and a threshold of ten zygotes was reached per culture by adding agar chip-embedded slaughterhouse presumed zygotes $(8 \sim 2)$. This variation in the number of COCs retrieved is consistent with other reports on cattle [1-3]. The number of COCs retrieved varies between individual donor cows [27-29]. Technical differences in OPU methods can also affect the number of COCs retrieved per OPU session $[6,30,31]$. In addition, variations in the number of COCs retrieved were observed between OPU sessions (data not shown). Therefore, it is difficult to culture the same number of OPU-derived presumed zygotes over the entire IVP process. The results of the present experiment are consistent with those of Senatore et al. [11] who cultured nine agar-embedded slaughterhouse presumed zygotes with one OPU zygote, seven with three OPU zygotes, and five with five OPU zygotes (i.e., nine zygotes added to one; seven added to three; five added to five) and compared the development rates of these cocultures to those of one, three and five OPU zygotes, respectively, each in a $50 \mu \mathrm{L}$ droplet of 
Table 2 In vitro development potential and quality of bovine presumed zygotes

\begin{tabular}{llllll}
\hline Culture system & Presumed zygote $(\mathbf{n})$ & $\begin{array}{l}\text { \% cleaved } \\
\text { (range in \%) }\end{array}$ & $\begin{array}{l}\text { \% blastocyst } \\
\text { (range in \%) }\end{array}$ & $\begin{array}{l}\text { Total blastomeres } \\
\text { (range) }\end{array}$ & $\begin{array}{l}\text { \% apoptotic blastomeres } \\
\text { (range in \%) }\end{array}$ \\
\hline ControlOPU & 201 & $64.3^{\mathrm{a}} \pm 32.0(0-100)$ & $13.9^{\mathrm{a}} \pm 18.1(0-57.1)$ & $118.3^{\mathrm{a}} \pm 24.4(65-163)$ & $4.6^{\mathrm{a}} \pm 2.0(1.3-7.5)$ \\
Agar OPU & 151 & $82.8^{\mathrm{a}} \pm 26.1(0-100)$ & $35.2^{\mathrm{b}} \pm 26.3(0-100)$ & $128.2^{\mathrm{a}} \pm 29.5(73-215)$ & $4.9^{\mathrm{a}} \pm 1.6(2.1-7.8)$ \\
S IVPy & 120 & $74.0^{\mathrm{a}} \pm 11.6(53.3-100)$ & $30.8^{\mathrm{b}} \pm 13.8(0-50.0)$ & $123.1^{\mathrm{a}} \pm 28.9(65-188)$ & $3.8^{\mathrm{a}} \pm 2.7(1-10.8)$ \\
dmapIVPz & 143 & $72.8^{\mathrm{a}} \pm 5.0(67.3-76.9)$ & $28.6^{\mathrm{b}} \pm 3.9(25.0-32.7)$ & $124.2^{\mathrm{a}} \pm 36.7(65-175)$ & $5.3^{\mathrm{a}} \pm 2.8(1.2-11.0)$ \\
\hline
\end{tabular}

Cleavage and blastocyst development rates were calculated based on total presumed zygotes transferred into IVC medium.

$\mathrm{a}, \mathrm{b}$ Values with different superscript letters within a column differ significantly $(P<0.01)$.

${ }^{x}$ Development rates are those of OPU cultured zygotes. The development rates of agar-embedded slaughterhouse embryos were not considered.

${ }^{y}$ A group of 10 COCs from slaughterhouse ovaries was used for IVP.

z Slaughterhouse COCs pre-treated with $2 \mathrm{mM}$ 6-dimethylaminopurine for $6 \sim 7 \mathrm{~h}$ before maturation followed by IVM, IVF and IVC.

medium. They reported that the development rate of OPU embryos cocultured with agar-embedded slaughterhouse helper embryos was superior to that of control embryos. The present study differs from that report in that the number of COCs collected during an OPU session from a single cow was considered as a unit of experimental replication. In addition, the present study assessed blastocyst quality by measuring blastomere numbers, the percentages of apoptotic blastomeres in the blastocysts and gene expression. The low development rate of OPU presumed zygotes in the controlOPU culture is not due to a compromised culture condition since $30.8 \%$ of the slaughterhouse presumed zygotes developed into blastocysts. Moreover, the agar does not affect the developmental competence of OPU embryos [11]. Therefore, the number of presumed zygotes per droplet may be the major determinant of compromised development in the controlOPU cultures.

Gopichandran and Leese [10] showed that, in cultures of multiple bovine embryos, the density and the distance between embryos determines the efficiency of embryo development. Moreover, the number of embryos per culture droplet is also important to embryo development [32-34]. The benefit of coculturing multiple embryos is likely due to the secretion of embryotrophic factors by the embryos during their development $[10,35,36]$. Several of these factors, including insulin-like growth factor (IGF)-I, IGF-II, platelet-activating factor $[10,37]$ and platelet-derived growth factor [38], have been investigated. These growth factors have positive effects on IVP, particularly at low embryo density. However, the effect of these embryo-derived factors on the agarOPU culture system is unknown.

Blastocyst quality is measured by the total number of blastomeres and by the percentage of apoptotic blastomeres $[23,25,39]$, which are inversely correlated with the post-transfer development potential of embryos [39-41]. The number of blastomeres and the percentage of apoptotic blastomeres in the blastocysts were evaluated by TUNEL assay. The level of apoptosis in the blastocysts was further confirmed by the detection of CSAP3
mRNA. No difference in the percentage of apoptotic blastomeres or CASP3 mRNA expression was detected among blastocysts from the three culture conditions. The number of blastomeres and the percentage of apoptotic blastomeres observed in blastocysts developed in the agarOPU, controlOPU and sIVP culture systems are consistent with published studies using OPU [7] and slaughterhouse [23] blastocysts. These results show that the agarOPU culture system has no adverse effect on the total number of blastomeres and does not promote blastomere apoptosis.

6-Dimethylaminopurine (DMAP), a serine threonine protein kinase inhibitor, can prevent the resumption of meiotic maturation in immature oocytes [42-44]. Slaughterhouse oocyte maturation was synchronized by pre-maturation exposure to DMAP for 6 to $7 \mathrm{~h}$ to coordinate the culture schedule of OPU-derived oocytes. The pre-treatment of oocytes with DMAP did not affect blastocyst rates, blastomere numbers or blastocyst apoptosis, which is inconsistent with previous studies of bovine oocytes [42-44]. Our experimental design differs from those studies in that immature oocytes were cultured with DMAP for a short period of time compared to the 12-24 h treatment used in those studies. Moreover, pre-treatment of human oocytes with DMAP for $7 \mathrm{~h}$ does not have any negative effect on embryo development [45]. These results show that the short-term pre-treatment of oocytes with DMAP has no effect on blastocyst development and quality. Therefore, the use of DMAP to synchronize the maturation of slaughterhouse COCs to the OPU schedule did not affect OPU embryo development in the agarOPU culture system.

$C D 9$, a member of the tetraspanin family, might be involved in embryo invasive behaviors [46]. The $A K R 1 B 1$ gene is potentially involved in pregnancy failure through metabolism of progesterone and synthesis of prostaglandin $\mathrm{F}_{2 \alpha}\left(\mathrm{PGF}_{2} \alpha\right)$ in the bovine uterine endometrium [17]. Aldose reductase induces apoptosis in cardiomyocytes [47]. High expression of these two genes in blastocysts correlates with the inhibition of embryo implantation and/or embryo resorption [20]. Therefore, 


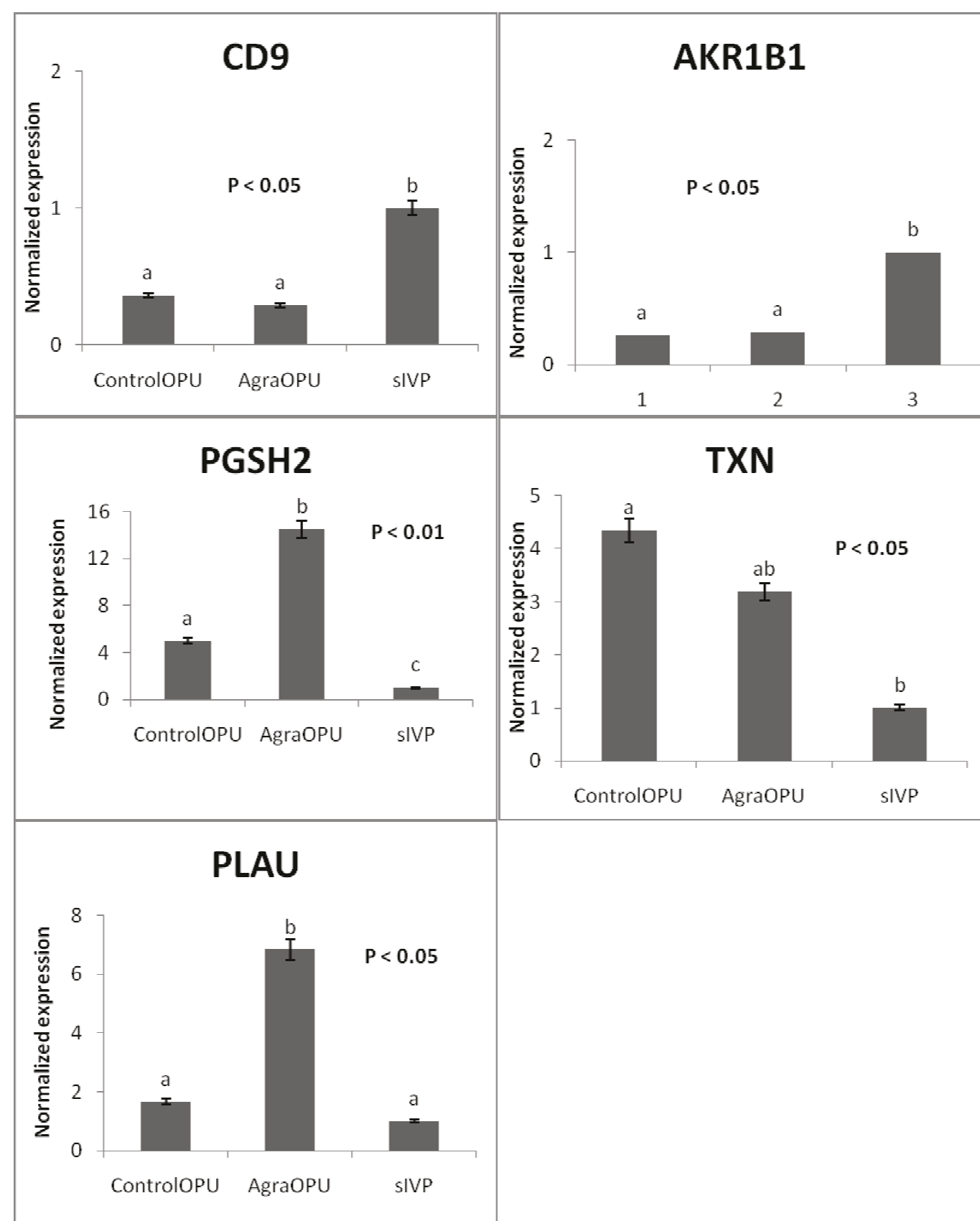

Figure 3 Gene expression of day 8 bovine blastocysts. Quantification of CD9, AKR1B1, PGSH2, TXN and PLAU genes in day 8 blastocysts developed from controlOPU (IVP with single cow presumed zygotes), agarOPU (IVP of single cow presumed zygotes with agar embedded slaughterhouse presumed zygotes) and sIVP (in vitro embryo production from slaughterhouse presumed zygotes) culture systems. In the agarOPU culture, only blastocysts developed from OPU presumed zygotes were used for gene expression analysis. Bars labeled with different letters differed significantly from each other.

down regulation of the $C D 9$ and $A K R 1 B 1$ genes in the agarOPU and controlOPU blastocysts might indicate improved embryo quality.

The PGSH2 gene is involved in the elongation and subsequent implantation process. Implantation and decidualization of the uterine stroma are impaired in
PGSH2-null mice [48]. Mutation of the gene encoding PGSH2 in mice leads to infertility [48-50]. Moreover, embryo-derived prostaglandins mediate the interaction of embryos with the uterus during implantation in sheep [51]. TXN is also involved in the implantation process [52] and in the prevention of oxidative stress 
during in vitro embryo development [52,53]. PLAU, which is involved in implantation in humans [54], mice [55] and rats [56], is abundant in the biopsies of bovine blastocysts that resulted in calf delivery [20]. PLAU mRNA was up-regulated in agarOPU cultures compared to control cultures. Low expression of PLAU is associated with implantation failure in mouse embryos [57]. These results collectively suggest that the high expression of the PGSH2, TXN and PLAU genes in OPU blastocysts may be an indicator of high quality embryos.

$P L A C 8$, an invasion-specific gene, is involved in placenta development and in the maintenance of the maternal-fetal interface. High expression of this gene in bovine blastocysts is associated with calf delivery [20]. Mouse embryos show a marked decrease in implantation when TGF-B2 is neutralized by the injection of neutralizing antibodies [58]. TGF-B1 favors trophoblast attachment and implantation by stimulating human cytotrophoblast cells to produce oncofetal fibronectin, which may serve as a trophoblast-uterine connecting protein [59]. ODC1-deficient murine embryos develop normally to the blastocyst stage and implant but die shortly thereafter [60]. Abundance of $O D C 1$ in bovine blastocysts is associated with subsequent resorption of embryos [20]. ATP5A1, which binds ATP, is abundant in biopsies of bovine blastocysts that do not result in pregnancy. However, the levels of PLAC8, TGF- $\beta 1$, $O D C 1$ and ATP5A1 transcripts did not differ between the three groups.

Two important concerns are associated with the commercial application of the agarOPU culture method: the possibility of disease transmission and the difficulty of handling embryos. Preventing contamination of OPU blastocysts by agar-embedded slaughterhouse helper embryos is the major challenge of the culture system. Blastocysts produced from slaughterhouse ovaries are sometimes contaminated with viruses, bacteria and other pathogenic agents [61]. Interestingly, the zona pellucida prevents penetration of these agents into intact oocytes and embryos during the course of in vitro maturation and culture [62]. Therefore, washing the embryos before freezing and/or transfer, as is recommended by the International Embryo Transfer Society [63], can minimize disease transfer to recipient cows. Moreover, recipient cows transferred with experimentally BVDV-contaminated blastocysts were not infected with the virus [64]. Therefore, blastocysts produced by the agarOPU method may be used for embryo transfer without any serious risk of disease transmission. Moreover, the preparation of agar chip-embedded helper embryos requires extra precautions so that the slaughterhouse embryos remain isolated from the OPU embryos throughout the culture period.

\section{Conclusions}

The present study demonstrated that the blastocyst development rates of small numbers of OPU-derived zygotes from a single cow can be improved by increasing the number of embryos per droplet through the coculture of slaughterhouse presumed zygotes with the OPU presumed zygotes. Moreover, the agarOPU coculture system has no adverse effect on embryo quality as measured by blastomere number, the percentage of apoptotic blastomeres in the blastocysts and gene expression. The agar chip-embedded helper embryo coculture system may be used in OPU-based IVP procedures to produce embryos of known genetic background from donor cows of high genetic merit.

\section{Acknowledgements}

The authors thank Dr. G.A. Presicce, Istituto Superiore della Sanità (ISS), Rome, Italy for his support and valuable guidelines regarding the OPU technique and for reviewing the manuscript. This work was supported by the Ministry for Food, Agriculture, Forestry and Fisheries, IPET, Republic of Korea (Grant \# 108068-03-1-SB010 and 110020-03-SB010). GKD was supported by a scholarship from the Korean Research Foundation (KRF). THK, BHC, JIB and SRD were supported by scholarships from the Post BK21 program of the Ministry of Education, Science and Technology, Republic of Korea.

\section{Author details}

'Division of Applied Life Science (BK21 program), Graduate School of Gyeongsang National University, Jinju 660-701, Republic of Korea. ${ }^{2}$ Central Branch of Gyeongnam Livestock Promotion Research Institute, Kimhae 621833, Republic of Korea. ${ }^{3}$ Institute of Agriculture and Life Science, Gyeongsang National University, Jinju 660-701, Republic of Korea.

\section{Authors' contributions}

GKD performed embryo culture, embryo staining for the detection of total and apoptotic blastomere numbers, and GPCR analysis. JJ performed OPU operations. THK, BHC and JIB managed donor cows and assisted with the OPU operations. SRD assisted with the in vitro embryo production from slaughterhouse ovaries and APCR analysis. IRC arranged donor cows for OPU operations. IKK reviewed the manuscript and supervised all experimental activities related to this manuscript. All authors read and approved the final manuscript.

\section{Competing interests}

The authors declare that they have no competing interests.

Received: 18 March 2011 Accepted: 24 August 2011

Published: 24 August 2011

\section{References}

1. Reis A, Staines ME, Watt RG, Dolman DF, McEvoy TG: Embryo production using defined oocyte maturation and zygote culture media following repeated ovum pick-up (OPU) from FSH-stimulated Simmental heifers. Anim Reprod Sci 2002, 72:137-151.

2. De Roover R, Feugang JM, Bols PE, Genicot G, Hanzen C: Effects of ovum pick-up frequency and FSH stimulation: a retrospective study on seven years of beef cattle in vitro embryo production. Reprod Domest Anim 2008, 43:239-245

3. Merton JS, Ask B, Onkundi DC, Mullaart E, Colenbrander B, Nielen M: Genetic parameters for oocyte number and embryo production within a bovine ovum pick-up-in vitro production embryo-production program. Theriogenology 2009, 72:885-893.

4. Manjunatha BM, Ravindra JP, Gupta PS, Devaraj M, Nandi S: Oocyte recovery by ovum pick up and embryo production in river buffaloes (Bubalus bubalis). Reprod Domest Anim 2008, 43:477-480. 
5. Petyim S, Bage R, Hallap T, Bergqvist AS, Rodriguez-Martinez H, Larsson B: Two different schemes of twice-weekly ovum pick-up in dairy heifers: effect on oocyte recovery and ovarian function. Theriogenology 2003, 60:175-188.

6. De Roover R, Bols PE, Genicot G, Hanzen C: Characterisation of low, medium and high responders following FSH stimulation prior to ultrasound-guided transvaginal oocyte retrieval in cows. Theriogenology 2005, 63:1902-1913.

7. Yang XY, Zhao JG, Li H, Liu HF, Huang Y, Huang SZ, Zeng F, Zeng YT: Effect of individual heifer oocyte donors on cloned embryo development in vitro. Anim Reprod Sci 2008, 104:28-37.

8. Machado SA, Reichenbach HD, Weppert M, Wolf E, Goncalves PB: The variability of ovum pick-up response and in vitro embryo production from monozygotic twin cows. Theriogenology 2006, 65:573-583.

9. Brum DS, Leivas FG, Silva CAM, Rubin MIB, Rauber LP, Fialho SS, Pilla LFC, Bernardi ML: The effects of number of oocytes and the volume of maturation medium in bovine in vitro embryo production. Animal Reproduction 2005, 2:70-73.

10. Gopichandran N, Leese HJ: The effect of paracrine/autocrine interactions on the in vitro culture of bovine preimplantation embryos. Reproduction 2006, 131:269-277.

11. Senatore EM, Xu J, Suarez Novoa MV, Gong G, Lin T, Bella A, Moreno JF, Mannino ME, Tian X, Presicce GA, Wu SC, Du F: Improved in vitro development of OPU-derived bovine (Bos taurus) embryos by group culture with agarose-embedded helper embryos. Theriogenology 2010, 74:1643-1651.

12. Wrenzycki C, Herrmann D, Carnwath JW, Niemann H: Expression of RNA from developmentally important genes in preimplantation bovine embryos produced in TCM supplemented with BSA.J Reprod Fertil 1998, 112:387-398.

13. Wrenzycki C, Herrmann D, Niemann H: Messenger RNA in oocytes and embryos in relation to embryo viability. Theriogenology 2007, , 68 Suppl 1: $577-83$.

14. Lonergan P, Rizos D, Gutierrez-Adan A, Fair T, Boland MP: Effect of culture environment on embryo quality and gene expression - experience from animal studies. Reprod Biomed Online 2003, 7:657-663.

15. Niemann $\mathrm{H}$, Wrenzycki C: Alterations of expression of developmentally important genes in preimplantation bovine embryos by in vitro culture conditions: implications for subsequent development. Theriogenology 2000, 53:21-34

16. Rizos D, Lonergan P, Boland MP, Arroyo-Garcia R, Pintado B, de la Fuente J, Gutierrez-Adan A: Analysis of differential messenger RNA expression between bovine blastocysts produced in different culture systems: implications for blastocyst quality. Biol Reprod 2002, 66:589-595.

17. Gomez E, Gutierrez-Adan A, Diez C, Bermejo-Alvarez P, Munoz M, Rodriguez A, Otero J, Alvarez-Viejo M, Martin D, Carrocera S, Caamano JN: Biological differences between in vitro produced bovine embryos and parthenotes. Reproduction 2009, 137:285-295.

18. Wrenzycki C, Herrmann D, Niemann H: Timing of blastocyst expansion affects spatial messenger RNA expression patterns of genes in bovine blastocysts produced in vitro. Biol Reprod 2003, 68:2073-2080.

19. Wrenzycki C, Herrmann D, Lucas-Hahn A, Lemme E, Korsawe K, Niemann H: Gene expression patterns in in vitro-produced and somatic nuclear transfer-derived preimplantation bovine embryos: relationship to the large offspring syndrome? Anim Reprod Sci 2004, , 82-83: 593-603.

20. El-Sayed A, Hoelker M, Rings F, Salilew D, Jennen D, Tholen E, Sirard MA Schellander K, Tesfaye D: Large-scale transcriptional analysis of bovine embryo biopsies in relation to pregnancy success after transfer to recipients. Physiol Genomics 2006, 28:84-96.

21. Godkin JD, Dore JJ: Transforming growth factor beta and the endometrium. Rev Reprod 1998, 3:1-6.

22. Stojkovic M, Machado SA, Stojkovic P, Zakhartchenko V, Hutzler $P$, Goncalves PB, Wolf E: Mitochondrial distribution and adenosine triphosphate content of bovine oocytes before and after in vitro maturation: correlation with morphological criteria and developmental capacity after in vitro fertilization and culture. Biol Reprod 2001, 64:904-909.

23. Jeong WJ, Cho SJ, Lee HS, Deb GK, Lee YS, Kwon TH, Kong IK: Effect of cytoplasmic lipid content on in vitro developmental efficiency of bovine IVP embryos. Theriogenology 2009, 72:584-589.
24. Rosenkrans CF Jr, Zeng GQ, GT MC, Schoff PK, First NL: Development of bovine embryos in vitro as affected by energy substrates. Biol Reprod 1993, 49:459-462.

25. Deb GK, Dey SR, Bang JI, Cho SJ, Park HC, Lee JG, Kong IK: 9-cis retinoic acid improves developmental competence and embryo quality during in vitro maturation of bovine oocytes through the inhibition of oocyte TNF-\{alpha\} gene expression. J Anim Sci 2011, 89:2759-2767.

26. The Primer Designing Tool. [http://www.ncbi.nlm.nih.gov/tools/primer-blast/].

27. Kruip TA, Boni R, Wurth YA, Roelofsen MW, Pieterse MC: Potential use of ovum pick-up for embryo production and breeding in cattle. Theriogenology 1994, 42:675-684.

28. Hasler JF, Henderson WB, Hurtgen ZQ, Jin ZQ, McCauley AD, Mower SA, Neely B, Shuey LS, Stokes JE, Trimmer SA: Production, freezing and transfer of bovine IVF embryos and subsequent calving results. Theriogenology 1995, 43:141-152.

29. Bruggerhoff $\mathrm{K}$, Zakhartchenko V, Wenigerkind $H$, Reichenbach HD, Prelle $K$, Schernthaner W, Alberio R, Kuchenhoff H, Stojkovic M, Brem G, Hiendleder S, Wolf E: Bovine somatic cell nuclear transfer using recipient oocytes recovered by ovum pick-up: effect of maternal lineage of oocyte donors. Biol Reprod 2002, 66:367-373.

30. Merton JS, de Roos AP, Mullaart E, de Ruigh L, Kaal L, Vos PL, Dieleman St: Factors affecting oocyte quality and quantity in commercial application of embryo technologies in the cattle breeding industry. Theriogenology 2003, 59:651-674.

31. Ward FA, Lonergan P, Enright BP, Boland MP: Factors affecting recovery and quality of oocytes for bovine embryo production in vitro using ovum pick-up technology. Theriogenology 2000, 54:433-446.

32. Garcia A, Salaheddine M: Effects of repeated ultrasound-guided transvaginal follicular aspiration on bovine oocyte recovery and subsequent follicular development. Theriogenology 1998, 50:575-585.

33. Fukui Y, Kikuchi Y, Kondo H, Mizushima S: Fertilizability and developmental capacity of individually cultured bovine oocytes. Theriogenology 2000, 53:1553-1565.

34. O'Doherty EM, Wade MG, Hill JL, Boland MP: Effects of culturing bovine oocytes either singly or in groups on development to blastocysts. Theriogenology 1997, 48:161-169.

35. Keefer CL, Stice SL, Paprocki AM, Golueke P: In vitro culture of bovine IVMIVF embryos: Cooperative interaction among embryos and the role of growth factors. Theriogenology 1994, 41:1323-1331.

36. Donnay I, Van Langendonckt A, Auquier P, Grisart B, Vansteenbrugge A, Massip A, Dessy F: Effects of co-culture and embryo number on the in vitro development of bovine embryos. Theriogenology 1997, 47:1549-1561.

37. O'Neill C: Evidence for the requirement of autocrine growth factors for development of mouse preimplantation embryos in vitro. Biol Reprod 1997, 56:229-237.

38. Thibodeaux JK, Del Vecchio RP, Hansel W: Role of platelet-derived growth factor in development of in vitro matured and in vitro fertilized bovine embryos. J Reprod Fertil 1993, 98:61-66.

39. van Soom A, Ysebaert MT, de Kruif A: Relationship between timing of development, morula morphology, and cell allocation to inner cell mass and trophectoderm in in vitro-produced bovine embryos. Mol Reprod Dev 1997, 47:47-56.

40. Chang YJ, Chan WH: Methylglyoxal has injurious effects on maturation of mouse oocytes, fertilization, and fetal development, via apoptosis. Toxicol Lett 2010, 193:217-223.

41. Pakrasi PL, Jain AK: Cyclooxygenase-2-derived endogenous prostacyclin reduces apoptosis and enhances embryo viability in mouse. Prostaglandins Leukot Essent Fatty Acids 2008, 79:27-33.

42. Dode MA, Adona PR: Developmental capacity of Bos indicus oocytes after inhibition of meiotic resuption by 6-dimethylaminopurine. Anim Reprod Sci 2001, 65:171-180.

43. Lonergan P, Khatir H, Carolan C, Mermillod P: Bovine blastocyst production in vitro after inhibition of oocyte meiotic resumption for 24 h. J Reprod Fertil 1997, 109:355-365.

44. Saeki K, Nagao Y, Kishi M, Nagai M: Developmental capacity of bovine oocytes following inhibition of meiotic resumption by cycloheximide or 6-dimethylaminopurine. Theriogenology 1997, 48:1161-1172.

45. Anderiesz C, Fong CY, Bongso A, Trounson AO: Regulation of human and mouse oocyte maturation in vitro with 6-dimethylaminopurine. Hum Reprod 2000, 15:379-388 
46. Liu WM, Cao YJ, Yang YJ, Li J, Hu Z, Duan EK: Tetraspanin CD9 regulates invasion during mouse embryo implantation. J Mol Endocrinol 2006, 36:121-130.

47. Galvez AS, Ulloa JA, Chiong M, Criollo A, Eisner V, Barros LF, Lavandero S: Aldose reductase induced by hyperosmotic stress mediates cardiomyocyte apoptosis: differential effects of sorbitol and mannitol. J Biol Chem 2003, 278:38484-38494

48. Lim H, Paria BC, Das SK, Dinchuk JE, Langenbach R, Trzaskos JM, Dey SK: Multiple female reproductive failures in cyclooxygenase 2-deficient mice. Cell 1997, 91:197-208

49. Dinchuk JE, Car BD, Focht RJ, Johnston JJ, Jaffee BD, Covington MB, Contel NR, Eng VM, Collins RJ, Czerniak PM, Gorry SA, Trzaskos JM: Renal abnormalities and an altered inflammatory response in mice lacking cyclooxygenase II. Nature 1995, 378:406-409.

50. Langenbach R, Morham SG, Tiano HF, Loftin CD, Ghanayem BI, Chulada PC, Mahler JF, Lee CA, Goulding EH, Kluckman KD, Kim HS, Smithies O: Prostaglandin synthase 1 gene disruption in mice reduces arachidonic acid-induced inflammation and indomethacin-induced gastric ulceration Cell 1995, 83:483-492.

51. Wang H, Wen Y, Mooney S, Behr B, Polan ML: Phospholipase A(2) and cyclooxygenase gene expression in human preimplantation embryos. J Clin Endocrinol Metab 2002, 87:2629-2634.

52. Bing YZ, Hirao Y, Takenouchi N, Che LM, Nakamura H, Yodoi J, Nagai T: Effects of thioredoxin on the preimplantation development of bovine embryos. Theriogenology 2003, 59:863-873.

53. Nonogaki T, Noda Y, Narimoto K, Umaoka Y, Mori T: Protection from oxidative stress by thioredoxin and superoxide dismutase of mouse embryos fertilized in vitro. Hum Reprod 1991, 6:1305-1310.

54. Khamsi F, Armstrong DT, Zhang X: Expression of urokinase-type plasminogen activator in human preimplantation embryos. Mol Hum Reprod 1996, 2:273-276.

55. Sappino AP, Huarte J, Belin D, Vassalli JD: Plasminogen activators in tissue remodeling and invasion: mRNA localization in mouse ovaries and implanting embryos. J Cell Biol 1989, 109:2471-2479.

56. Aflalo ED, Sod-Moriah UA, Potashnik G, Har-Vardi I: Differences in the implantation rates of rat embryos developed in vivo and in vitro: possible role for plasminogen activators. Fertil Steril 2004, 81(Suppl 1):780-785.

57. Axelrod HR: Altered trophoblast functions in implantation-defective mouse embryos. Dev Biol 1985, 108:185-190.

58. Slager HG, Van Inzen W, Freund E, Van den Eijnden-Van Raaij AJ, Mummery CL: Transforming growth factor-beta in the early mouse embryo: implications for the regulation of muscle formation and implantation. Dev Genet 1993, 14:212-224

59. Feinberg RF, Kliman HJ, Wang CL: Transforming growth factor-beta stimulates trophoblast oncofetal fibronectin synthesis in vitro: implications for trophoblast implantation in vivo. J Clin Endocrinol Metab 1994, 78:1241-1248.

60. Pendeville H, Carpino N, Marine JC, Takahashi Y, Muller M, Martial JA, Cleveland $\mathrm{J}$ : The ornithine decarboxylase gene is essential for cell survival during early murine development. Mol Cell Biol 2001, 21:6549-6558.

61. Guerin B, Le Guienne B, Thibier M: A secure health status associated with the production and trade of in vitro derived cattle embryos. Livest Prod Sci 2000, 62:271-285.

62. Tsuboi T, Imada T: Effect of bovine herpes virus-1, bluetongue virus and akabane virus on the in vitro development of bovine embryos. Vet Microbiol 1997, 57:135-142.

63. Stringfellow DA: Recommendations for the sanitary handling of in vivo derived embryos. In Manual of the International Embryo Transfer Society. 3 edition. Edited by: Stringfellow DA, Seidel SM. International Embryo Transfer Society, Savoy, Illinois, USA; 1998:143-149.

64. Given MD, Riddell KP, Galik PK, Stringfellow DA, Brock KV, Loskutoff NM: Diagnostic dilemma encountered when detecting bovine viral diarrhea virus in IVF embryo production. Theriogenology 2002, 58:1399-1407.

doi:10.1186/1477-7827-9-121

Cite this article as: Deb et al: Improved blastocyst development of single cow OPU-derived presumptive zygotes by group culture with agarose-embedded helper embryos. Reproductive Biology and Endocrinology 2011 9:121.

\section{Submit your next manuscript to BioMed Central and take full advantage of:}

- Convenient online submission

- Thorough peer review

- No space constraints or color figure charges

- Immediate publication on acceptance

- Inclusion in PubMed, CAS, Scopus and Google Scholar

- Research which is freely available for redistribution 